Portland State University

PDXScholar

\title{
A longitudinal study of disfluencies in the speech of normal preschool children
}

Susan Marto Crowell

Portland State University

Follow this and additional works at: https://pdxscholar.library.pdx.edu/open_access_etds

Part of the Speech Pathology and Audiology Commons

Let us know how access to this document benefits you.

\section{Recommended Citation}

Crowell, Susan Marto, "A longitudinal study of disfluencies in the speech of normal preschool children" (1989). Dissertations and Theses. Paper 3870.

https://doi.org/10.15760/etd.5754

This Thesis is brought to you for free and open access. It has been accepted for inclusion in Dissertations and Theses by an authorized administrator of PDXScholar. Please contact us if we can make this document more accessible: pdxscholar@pdx.edu. 
AN ABSTRACT OF THE THESIS OF Susan Marto crowe 11 for the Master of Science in Speech Communication with an emphasis in Speech Pathology presented April 5, 1989.

Title: A Longitudinal study of Disfluencies in the speech of Normal Preschool Children.

APPROVED BY THE MEMBERS OF THE THESIS COMMITTEE:

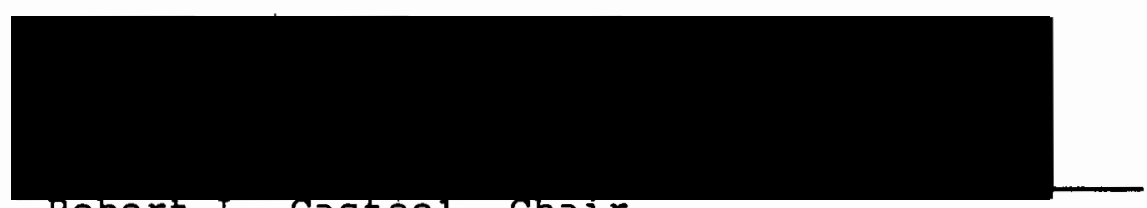
Robert L. casteel, chair

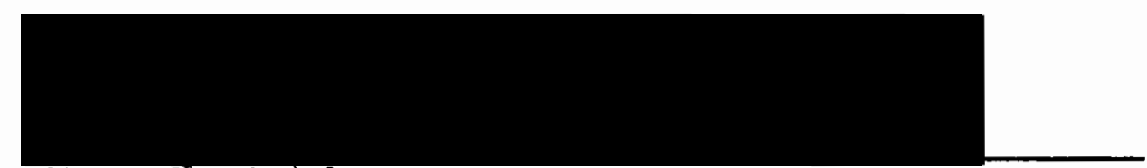

Mary E. Gojaon

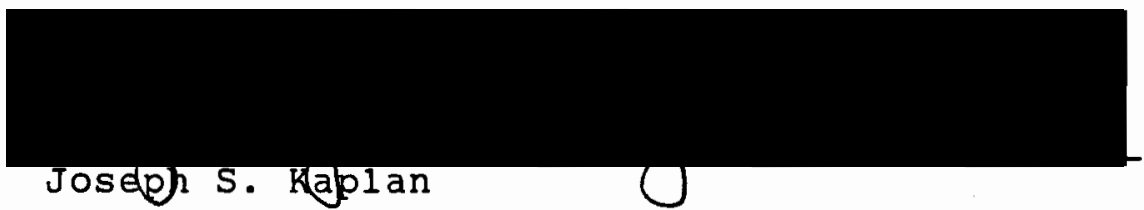

The process of differentially diagnosing a child who is experiencing temporary normal disfluency from one who is beginning to stutter could be made objective by the establishment of normative data on fluency development. To date, there are no standardized norms on the development of fluency in children. Current investigations have contributed greatly to expectations of certain types and amounts of disfluencies in preschool-age children. Most of the research, however, has focused on observing children at discrete age levels from 
2 - to 7-years-of-age. Only one longitudinal study to date has been reported. Additional longitudinal data of preschoolaged children would benefit the establishment of normative data. Observing the same children over time helps to expose the subtleties that could be missed when looking only at specific age levels. The present study sought to contribute to the investigation of normal childhood disfluency by comparing various types and amounts of disfluencies in 44- to 49-month-old-children to the results of the same group of children when they were 30 - to 35-months-of-age.

Fifteen male subjects ranging in age from 44 to 49 months participated as subjects. The 15 subjects were drawn from the 20 subjects who participated in the original Herrick study done in 1987. Subjects were videotaped for 15 minutes during free play with toys and during conversation with the investigator. Speech samples were analyzed for the following nine disfluency types: sound repetitions, syllable repetitions, single syllable word repetitions, multisyllable word repetitions, phrase repetitions, revisionincomplete phrases, interjections, disrhythmic phonations, and tense pauses.

The analysis of data revealed that syllable repetitions were the single disfluency type to change significantly, by decreasing, over a 12 - to 14 -month period in a group of 44to 49-month-old children. The total of low risk disfluency types (interjections, revision-incomplete phrases, phrase repetitions, and multisyllable word repetitions) occurred 
more frequently than did the total of high risk disfluency types (sound and syllable repetitions, single syllable word repetitions, disrhythmic phonations, and tense pauses). The rank order of disfluencies changed slightly over a one-year period. The rank order for the individual children revealed a somewhat moderate association between how they ranked in 1987 and in 1988 , although not at a statistically significant level of confidence.

The findings of the present study did not support the trend found in the literature for a decrease in overall disfluency with an increase in chronological age. The total of repetition type disfluencies (sound and syllable repetitions, single syllable and multisyllable word repetitions) all decreased in frequency (phrase repetitions remained nearly the same). Interjections, revision-incomplete phrases, disrhythmic phonations, and tense pauses, however, all increased in frequency. The findings of the current study are consistent with recent studies which support a decrease of part word repetitions with an increase in chronological age. Also consistent with most of the related studies is the finding that revision-incomplete phrases and interjections are the most frequently occurring disfluency types in normal speaking children. Finally, the findings of the present study support the longitudinal data from a 1982 investigation done by Yairi of 2-year-old children that a high degree of variability exists in patterns of disfluency from one year to the next. 


\title{
A LONGITUDINAL STUDY OF DISFLUENCIES IN THE SPEECH OF NORMAL PRESCHOOL CHILDREN
}

\author{
by
}

SUSAN MARTO CROWELI

A thesis submitted in partial fulfillment of the requirements for the degree of

\author{
MASTER OF SCIENCE \\ in \\ SPEECH COMMUNICATION: \\ with an emphasis in \\ SPEECH-LANGUAGE PATHOLOGY
}

Portland State University

1989 
TO THE OFFICE OF GRADUATE STUDIES:

The members of the Committee approve the thesis of Susan Marto Crowell presented April 5, 1989.
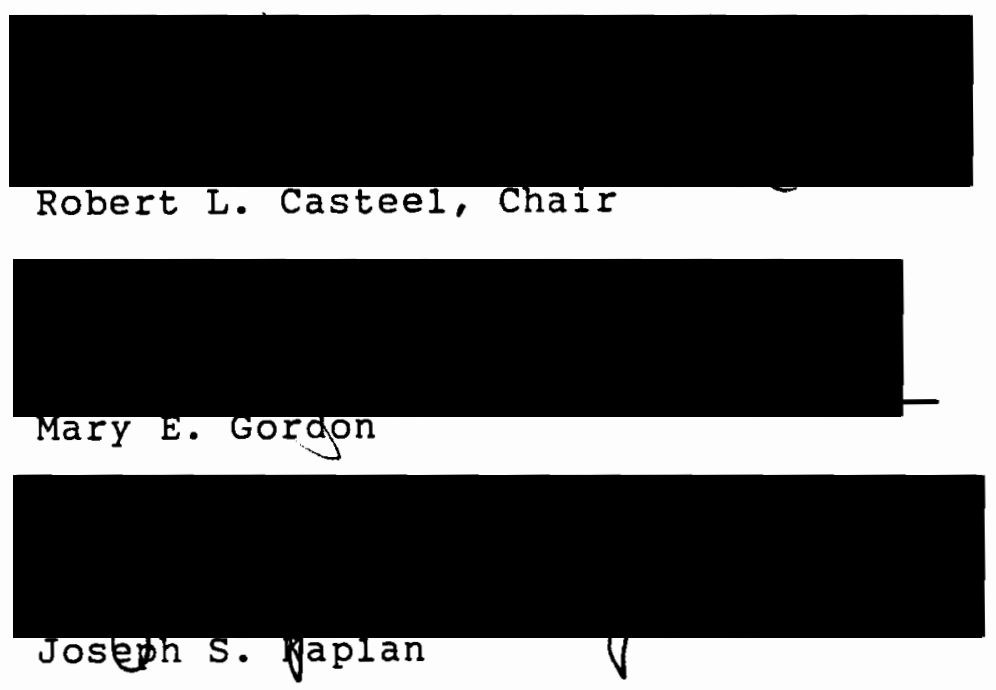

APPROVED:

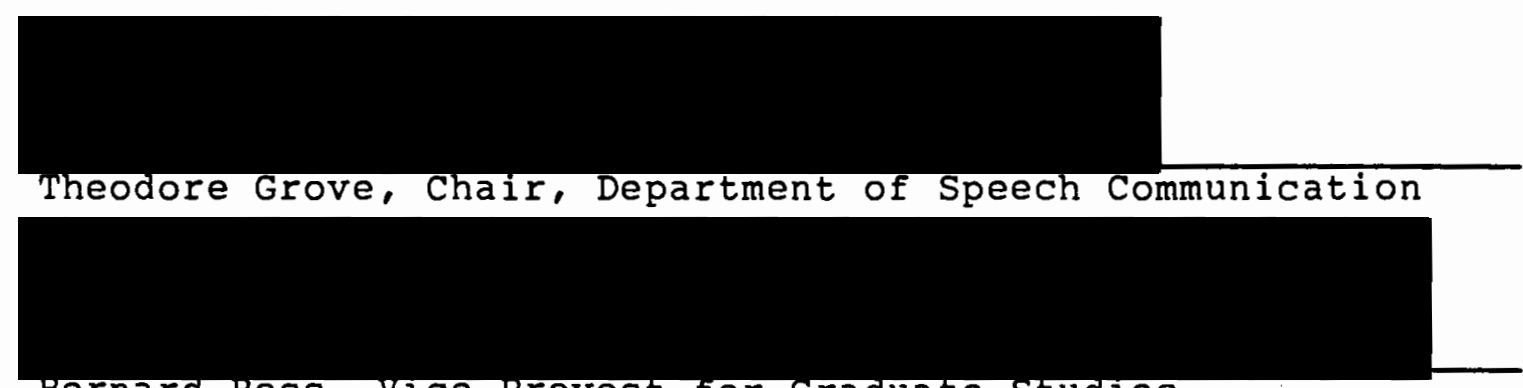

Bernara Ross, vice provost for Graduate studies 


\section{ACKNOWLEDGMENTS}

My sincere thanks to Dr. Robert L. Casteel, who invited me to participate in this ongoing fluency research project. His guidance, encouragement, humor, expertise, and faith in me were instrumental in seeing this thesis through to its end.

I would like to thank Mary Gordon for her editing and help with statistical questions. Her interest and encouragement were invaluable. I also wish to thank Dr. Joseph Kaplan for sitting on my thesis committee.

A big thanks goes to Mary Cox and Annette O'Connell for serving as reliability judges.

A very special thanks to my mother-in-law, Margaret $M$. Crowell for her encouragement and support shown through lovingly babysitting her granddaughter, Jessica, in order that I could complete this project. The same goes to my mother, Juliette Marto, and sister, Angela, for babysitting when they could and similarly rallying behind me.

Most of all, I wish to thank my patient husband, Patrick, for his steadfast love and faith in me. 
TABLE OF CONTENTS

PAGE

ACKNOWLEDGMENTS . . . . . . . . . . . . . . . . iii

LIST OF TABLES . . . . . . . . . . . . . . . vi vi v

\section{CHAPTER}

I INTRODUCTION AND STATEMENT OF PURPOSE $\cdot$...$\quad 1$

Introduction . . . . . . . . . . . 1

Statement of Purpose . . . . . . . . 2

Definition of Terms . . . . . . . . . 3

II REVIEW OF THE LITERATURE . . . . . . . . 6

Validity of Past Investigations . . . . 6

Recent Investigations of Normal

Disfluency . . . . . . . . . . 8

An Amalgamation of Research on Normal

Disfluency and Stuttering . . . . . 17

Summary of Current Research . . . . . 21

III METHODS . . . . . . . . . . . 25

Subjects . . . . . . . . . . . 25

Subject Eligibility Procedures . . . . . 26

Speech Sample Procedures . . . . . . 27

Scoring Procedures . . . . . . . . 27

Reliability . . . . . . . . 28

Data Analysis . . . . . . . . . 28 
IV RESULTS AND DISCUSSION • . • • • • • •

Results • . . . . . . . . . . . .

Questions

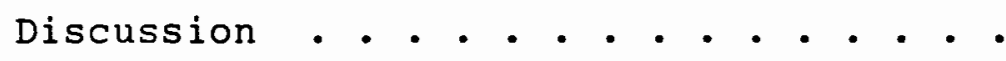

Comparisons of Disfluency Occurrence Rank Order of Disfluencies Compared Comparison of Trends

V SUMMARY AND IMPLICATIONS • • . • • • • • •

Summary • • • • • • . . • • • • • •

Implications

Clinical

Research

REFERENCES

APPENDIX

A Recruitment Letter . . . . . . . . .

B Consent Form . . . . . . . . . . . .

C Iist of Stimuli . . . . . . . . . . . .

D Rules for Calculating Word Samples . . . .

E Rules for Identifying Disfluencies . . .

F Coding symbols . . . . . . . . . . . .

$G$ Instructions for selection of content Transcripts for Reliability Testing . • .

$\mathrm{H}$ Instructions to Reliability Judges . . . . 


\section{LIST OF TABLES}

TABLE

PAGE

I Protocol for Differentiating the Incipient

stutterer . . . . . . . . . . . . . 20

II Results of a Two-Tailed $t$-Test for Dependent

Measures Comparing the Means of Frequencies

of Occurrence for Disfluency Types in 1987

and 1988 . . . . . . . . . . . . . .

II Rank Order of Al1 Disfluency Types Exhibited

in 1988 with the Corresponding 1987

Rankings . . . . . . . . . . . . . .

IV Results of the Spearman Rank-ordered Correlation

(rho) for How Each Child Ranked in 1987 and

1988 and Their Overal1 Disfluency Mean . . . 


\section{CHAPTER I \\ INTRODUCTION AND STATEMENT OF PURPOSE}

\section{INTRODUCTION}

The speech-language pathologist must differentially diagnose a child who has begun to stutter from a child who is experiencing temporary normal disfluency. Proficient diagnosis is required either to hasten clinical intervention, provide counseling, or to avoid unwarranted intervention (Adams, 1980). In order to determine a diagnosis, the speechlanguage pathologist must know what constitutes normal disfluency. A problem is that the types of disfluencies seen in the speech of normally-speaking children can also be observed in the speech of children who stutter (Bloodstein, 1974). An additional difficulty is that the onset of normal disfluency and the onset of stuttering frequently overlap in preschool-age children.

There are no standardized norms at the present on the development of fluency in children. Results from research on fluency development from several landmark studies of the $1930^{\prime}$ 's and 1940's have come under attack by present day investigators who question the procedures and validity of the earlier studies (DeJoy and Gregory, 1985; Wexler and Mysak, 1982; Yairi, 1981). 
Studies which look at the disfluencies of children at discrete age levels vary a great deal, partly due to small sample size and to large standard deviations. Even the one longitudinal study to date (Yairi, 1982) demonstrated great individual variance. Clearly further investigation in this area is timely and needed.

\section{STATEMENT OF PURPOSE}

The purpose of this study was to compare various types and amounts of disfluencies in 44- to 49-month-old children to the types and amounts of disfluencies of the same group of children when they were 30-to 35-months-of-age. Specifically, the following disfluency types were compared: part word repetitions, including sound and syllable repetitions, including single syllable and multisyllable word repetitions; phrase repetitions; revision-incomplete phrases; interjections; disrhythmic phonations; and tense pauses.

The study sought to answer the following primary question:

Does the frequency of occurrence of disfluencies change over a 12- to 14-month period in a group of normal 44- to 49-month-old children when compared to their performance at 30 - to 35-months-of-age?

The following secondary questions were addressed:

1. How does the rank order of specific types of disfluencies compare over time? 
2. How does the rank order of the individual children with regard to degree of disfluency compare over time?

\section{DEFINITION OF TERMS}

The following operational definitions are given to help clarify the terms used in this study.

1. Disfluency. Refers to all types of disruption in the rhythm or smooth flow of speech (Bloodstein, 1987; Wingate, 1964, 1987).

2. Disrhythmic phonation. Refers to audible or silent continuation of a sound or articulatory posture which interferes with the rhythmic flow of speech. Disrhythmic phonation is also referred to as prolongation. This type of disfluency occurs within words and includes broken words. Example: "I was g---oing home" (Bloodstein, 1987; Williams, Silverman, and Kools, 1968; Yairi, 1981).

3. Fluency. Refers to speech that is produced effortlessly with normal rate and rhythm or flow.

4. Frequency. Refers to the number of disfluencies per 100 words of speech (Riley, 1972).

5. Incipient stuttering. Refers to disfluent speech behavior which is determined by type and degree to signal the advent of chronic stuttering.

6. Interjection. Refers to extraneous sounds such as "uh," "er," "um," and "well" that do not add meaning to a speaker's text (Johnson, 1959). 
7. Intrusive schwa. Refers to the presence of the neutral schwa vowel intruding on the intended vowel. Example: "buh-buh-baby" (Van Riper, 1971).

8. Multisyllable word repetition. Refers to a word that has more than one syllable and is repeated in its entirety. Example: "cowboy-cowboy." This is also referred to as whole word repetition.

9. Normal disfluency. Refers to disfluent speech behavior that is demonstrated to some degree by nearly all speakers but is not considered likely to develop into chronic stuttering or warrant intervention.

10. Part word repetition. Refers to repetitions of sound and syllable units which are less than the entire word. Example: "s-s-sun" is a sound repetition and "ta-ta-tape is is a syllable repetition.

11. Phrase repetition. Refers to the repetition of two or more words. Example: "He was-he was-he was my friend."

12. Prolongation. Refers to any sound or syllable produced that is continued beyond that which is considered normal in length (see disrhythmic phonation).

13. Revision-incomplete phrase. Refers to instances in which modifications to a phrase are made in order to change the content, grammar, or pronounciation. Example: "I want, do you want some?" or "I buy, I bought some." This term has been used interchangeably with false-starts in some of the literature. 
14. Single syllable word repetition. Refers to a one syllable word which is repeated in its entirety more than once. Example: "boy-boy." This is also referred to as a whole word repetition.

15. Sound repetition. Refers to the repetition of a single speech sound in a word (see part word repetition). Example: "s-s-sun."

16. Stuttering. Refers to disfluent speech that is perceived to be abnormal, usually indicated by type and degree.

17. Syllable repetition. Refers to the repetition of a syllable in a word. Example: "bas-bas-basket." (See part word repetition.)

18. Tense pause. Refers to disfluency which is unintentionally produced between part words, words, and nonwords when at the between-point in question there are barely audible manifestations of heavy breathing or muscular tightening. When the phenomenon takes place within a word the disfluency is categorized as disrhythmic phonation (Williams, Silverman, and Kools, 1968).

19. Whole word repetition. Refers to the repetition of an entire word within an utterance. This includes single syllable and multisyllable words. 


\section{CHAPTER II}

\section{REVIEW OF THE LITERATURE}

\section{VALIDITY OF PAST INVESTIGATIONS}

Much of what is commonly known about normal disfluencies in the speech of preschool-aged children is based in part on the data obtained from several landmark studies. These studies (Branscom, Hughes, and Oxtoby, 1955; Davis, 1939) were conducted at the University of Iowa in the 1930's and 1940 's under the direction of Wendell Johnson (1955).

Based on his observations, as well as those of his graduate students, Johnson formed the opinion that most children display a certain amount of disfluent speech and therefore disfluency is a normal developmental phenomenon. He thus hypothesized that the distinguishing factor between a normally disfluent child and one who had begun to stutter, would be an overreaction by the parents to their child's disfluent speech (Johnson, 1959). Yairi (1981) points out that the Iowa studies lent credence to Johnson's diagnosogenic theory of stuttering. This hypothesis postulated that stuttering started in the ear of the listener rather than the mouth of the speaker, since all children in the various studies were disfluent to some degree. Thus the critical reaction displayed by a parent set up the conditions conducive to the development of incipient stuttering. 
Since Johnson emphasized the normality of disfluent speech in preschool children, normal disfluency has been a topic of import to researchers. His early data may have created an artificial overlap of nonstutterers and incipient stutterers when simply evaluating these two groups in regard to repetitions.

The validity of the data from the Iowa studies has been questioned by present-day investigators for a variety of reasons (DeJoy and Gregory, 1985; Wexler and Mysak, 1982; Yairi, 1981). One concern is how accurate previous investigators were in hand recording disfluencies as the children talked. Electronic equipment was lacking at the time and this most likely limited the accuracy of recording fluent and disfluent speech. Another concern was the limited range of disfluency types that were observed and recorded. The earlier studies mainly focused on observing repetitions. In excluding the other disfluency types or in grouping them together, only an incomplete analysis of normal disfluency could be done. Starkweather (1986) contended that when disfluency types are grouped together the "developmental effects are masked." Another problem with the Iowa studies is the insufficient number of subjects used in some investigations (Wexler, 1982). In some studies, results were reported for combined ages, as was the case in Johnson's (1959) study which reported on the combined age range from 2 to 8 years. Yairi (1981) pointed out that too few children at the lowest age level were represented in all the Iowa studies (25) to draw valid 
conclusions of developmental disfluency in the youngest group. Concerns also exist regarding the lack of a universal definition of disfluency and the encompassing disfluency types. This lack of agreement of a definition makes it difficult to identify disfluency as normal or disordered or to draw conclusion from study to study. Finally, a fundamental problem of earlier, as well as later, investigations is the absence of longitudinal data. Yairi (1981, 1982) maintained that incomplete conclusions are drawn about the developmental sequences of disfluency when studies focus on subjects representing different age groups. The studies fail to describe the short term variations in the same subject's speech and the developmental changes that occur over time.

\section{RECENT INVESTIGATIONS OF NORMAL DISFLUENCY}

As normal disfluency has come to be viewed as an expected phenomenon of preschool childrens' speech, researchers have sought to establish more comprehensive developmental disfluency data (DeJoy and Gregory, 1985; Starkweather, 1986; Wexler and Mysak, 1982; Yairi, 1981, 1982). This interest in normal disfluency development exists not only for reasons of differential diagnosis, but also in the theoretical interest of the possible relationship between stuttering and normal disfluency (DeJoy and Gregory, 1985 ; Yairi, 1981).

The attempt to establish more comprehensive normal disfluency data has involved observations of children at 
discrete age levels from 2 to 6 years (DeJoy and Gregory, 1985). It is during this age range that normal disfluency is exhibited (Wood, 1976). It is also the age range during which the onset of stuttering is most often observed (DeJoy and Gregory, 1985; Perkins, 1983; Sheehan, 1975).

Herrick (1987) investigated the frequency of occurrence of nine disfluency types in 20 males between the ages of 30 and 36 months. The following list reveals the ranked order for the frequency of occurrence of disfluency types: revision-incomplete phrases, single syllable word repetitions, part word repetitions (sound and syllable combined), interjections, phrase repetitions, disrhythmic phonations, multisyllable word repetitions, and tense pauses. The mean for the total number of disfluencies per 100 words was 4.90 with a standard deviation of 8.74 and a range of 1 to 15.66 . Herrick arranged her subjects in ranked order from least to most disfluent for repetition type of disfluencies. The subjects were then grouped into quartiles. Interestingly, a systematic increase from the first quartile to the last was observed for the frequency of repetitions. The fourth quartile alone equalied the sum of the combined first three quartiles.

The findings of Herrick's study indicated that the occurrence of multiple repetitions in the speech of $30-$ to 36-month-old children is common. Although some subjects did not exhibit any repetitions, and others rarely did, the fourth quartile subjects produced 10 times more repetitions 
than did the first quartile subjects. Davis (1939) concluded in her study that repetitions are part of the speech behavior of all children. While Herrick's data showed repetitions to be fairly consistent in the speech patterns of her subjects, 2 of her subjects produced only one repetition in their speech samples and another 2 subjects did not exhibita single repetition. This finding is also discussed by Yairi (1981) who writes that although, in principle, repetitions may be part of the speech behavior of children, not all children exhibit repetitions. Over $50 \%$ of Yairi's subjects had one repetition or less in 100 words. The repetitions usually included one extra production of a repeated segment. Yairi cautions that the concept of normal disfluency should not be taken to mean "frequently occurring or predictable behavior." From his results as well as Davis' findings, he suggests that many 2-year-olds demonstrate disfluent speech infrequently.

Arnold-Cockburn (1987) compared the frequency of occurrence of part word repetitions, whole word repetitions, and false starts (revision-incomplete phrases) in two groups of female children from video recordings of spontaneous speech samples. One group was composed of 10 females between the ages of 30 and 36 months and the other group had 10 females between 54- and 60-months-of-age. The ranked order for frequency of occurrence for disfluencies observed in the 30to 36-month-old group is as follows: part word repetitions, word repetitions, and revision-incomplete phrases. In the 54- to 60-month-o1d group, the order showed word repetitions 
ranking highest, then revision-incomplete phrases followed by part word repetitions. Results indicated that a statistically significant difference existed between the two groups for part word repetitions with the 30 - to 36 -month-old group exhibiting significantly more than did the older group. No other statistically significant differences were found for the remaining two disfluency types between both groups, nor for the overall number of disfluencies demonstrated. The Arnold-Cockburn (1987) study indicated that part word repetitions may be a good indicator of speech immaturity in older preschool children. This is in agreement with Yairi's 1982 study as well as Starkweather's (1986) contention, that part word repetitions represent the most immature type of speech disfluency and may be a prognosticator of incipient stuttering.

Yairi, in his 1981 study, analyzed eight types of dis-, fluencies in 2-year-olds. The group was comprised of 33 children, 18 girls and 15 boys. No significant sex differences were reported, but the results showed extreme individual variability. The total number of disfluencies per 100 words ranged from 0 to 25.6. Approximately half the subjects had less than 6 disfluencies per 100 words and the other half exhibited from 6 to 13 disfluencies when throwing out the highest and lowest scores of the 2 extreme subjects. All eight disfluency types were represented in the spontaneous speech samples, however not all subjects displayed all eight types. A rank ordering for the frequency of occurrence from 
most to least frequent of all disfluency types for males and females combined were as follows: interjections, single syllable word repetitions, part word repetitions, revisions, phrase repetitions, tense pauses, disrhythmic phonations, and multisyliable word repetitions. Part word repetitions, single syllable word repetitions, interjections, and revisions were the dominant fluency types exhibited by subjects, accounting for over $76 \%$ of the total number of disfluencies. The standard deviations in 5 of the 8 categories exceeded the group mean and in the remaining 3 categories were nearly equal to the mean. Yairi concluded that the data show that 2-year-olds are only homogenous with respect to being disfluent and that group averages do not carry much practical meaning at this age.

Two major trends emerged from Yairi's (1981) investigation of the disfluencies of 2-year-olds. First, repetitions of short segments of one syllable or less were a dominant speech behavior. When part word repetitions and single syllable repetitions were combined, they comprised almost $39 \%$ of the disfluency types tabulated; whereas repetitions of longer segments as in multisyllable word repetitions and phrase repetitions made up less than $10 \%$ of that total. Yairi pointed out that his findings contradict Davis' (1939) findings in that she observed that her subjects used more phrase repetitions than word or syllable repetitions. The second trend observed to be a dominant part of the subjects' speech behavior was the presence of 
revisions and interjections as forms of hesitancy. A combined count of these disfluency types was $37 \%$ of total disfluencies exhibited. A final noteworthy finding of Yairi's study was seen when he rank ordered his subjects from least to most disfluent and then divided the subjects into quartiles. The data revealed a systematic increase from one quartile to the next for all disfluency types with the exception of multisyllable word repetitions. The fourth quartile alone equalled the sum of the other three quartiles combined.

Yairi (1982) conducted a longitudinal study of the same group of children who participated as subjects in his 1981 study over a one-year period. The subjects' speech samples were obtained every 4 months. Although not the original intention of the investigator, two subgroups emerged from the 33 subjects. The two groups displayed dissimilar patterns of disfluency development. Subgroup I was composed of 13 children with a mean age of 25 months. Subgroup II contained 20 children with a mean age of 32 months. Subgroup I was seen for an additional fourth month interval to assure seeing them through their third birthday. Eight disfluency types were identified and classified consistent with the design of the 1981 study. Subgroup I showed a steady increase, with a temporary drop between the second and third testing period, from the beginning to the end of the study for the total number of disfluencies exhibited, while subgroup II showed a decline. The increase of disfluencies for the 
younger subgroup was primarily seen for the disfluency types of revisions and phrase repetitions. Subgroup II showed a consistent decline across all disfluency types, but mainly for part word repetitions and interjections. Yairi made four major observations based on his data. First, at the beginning of age 2 , the number of disfluencies are relatively sma11. Second, by the last quarter of the year, disfluencies reached a brief peak followed by a decline. Third, the number of disfluencies may increase and decrease significantly in the speech of many children at this age. Fourth, disfluencies that increased with age were primarily revisions and phrase interjections. Yairi summarized his data by stating, "The year between two and three is a volatile period in speech development as far as the parameter of disfluency is concerned" (1982, p. 159). He also cautions that in future studies of normal disfluency, 2-year-old children should not be treated as a single age group because of the high degree of variability in speech disfluency from younger to older 2-year-o1ds.

In a study of the relationship between age and frequency of disfluency in 60 normal males, 3.5- to 5-yearsof-age, DeJoy and Gregory (1985) found an overall trend toward less disfluency with an increase of chronological age. However, while certain categories of disfluencies decreased with chronological age (part word repetitions, word repetitions, phrase repetitions, revisions, incomplete phrases, and disrhythmic phonations), interjections declined 
only slightly and the category of tense pauses even rose slightly when combining grammatical and ungrammatical pauses. The investigators attributed this to the possibility of 5-year-olds using more sophisticated language structures. The researchers also pointed out that the use of interjections and tense pauses are among the types of disfluencies exhibited in adult speech.

In a rank order of frequency of occurrence for disfluency types from most to least frequent, the following order was observed for both groups: revisions and incomplete phrases, tense pauses (primarily ungrammatical), interjections, word repetitions, phrase repetitions, disrhythmic phonations, and part word repetitions. The findings in terms of absolute frequency of occurrence and trend toward less disfluency with an increase in chronological age are consistent with those of Wexler and Mysak (1982) and ArnoldCockburn (1987).

The studies of Wexler (1982) and Wexler and Mysak (1982) analyzed seven disfluency types in neutral and stress situations in the speech of 2- 4- and 6-year-old normal males. The two most frequently occurring disfluency types among all age groups were revision-incomplete phrases and interjections, showing no alterations when comparing neutral and stress situations. More often than not, particularly among 2- and 4-year-olds, the frequency of occurrence of each disfluency type analyzed showed a downward trend from neutral to stress situations. Wexler and Mysak hypothesized 
that the trend for less disfluency in stress situations may be due to several variables. First of all, the children may have been trying to speak as well as possible. A second variable may have been the application of an insufficient amount of stress. Finally, the design of the stress situation may have been inadequate to provoke speech disfluency. Wexler and Mysak contrasted their findings with those of Van Riper (1973). Van Riper's observations of stutterers showed that in stressful situations, they tend to be more disfluent; whereas, when Wexler and Mysak employed the same format as Van Riper to elicit disfluency in nonstutterers, the reverse happened.

Overal1, the Wexler and Mysak (1982) data confirms the trend for less disfluency with an increase of chronological age particularly from 2- to 4-years-of-age. The differences were negligible from the 4-to 6-year-old groups in their study.

Paguia-Christianson (1987) compared seven disfluency types in normal 3- and 5-year-old children. No statistically significant difference existed for the total frequency of disfluencies exhibited by the two groups. However, her findings did indicate that the 5-year-old group tended to demonstrate a higher overall frequency of occurrence of disfluencies. This may have been due to 2 disfluent subjects in the 5-year-old group. A statistically significant finding in her study existed for the 5-year-old group displaying a higher incidence of interjections than the 3-year-olds. 
While no statistically significant differences existed for the total frequency of occurrence between the two groups, the 3-year-old children exhibited a higher frequency of part word repetitions, word repetitions, and phrase repetitions. The 5-year-old group had a higher incidence of interjections, revision-incomplete phrases, and disrhythmic phonations. Interjections, revision-incomplete phrases, word repetitions, and phrase repetitions were the most common types of disfluencies occurring in both groups.

\section{AN AMALGAMATION OF RESEARCH ON NORMAL DISFLUENCY AND STUTTERING}

Researchers are approaching consensus as to the characteristics of normal disfluency. Researchers already generally agree upon the dominant characteristics of incipient stuttering. An area in which investigators have not completely agreed is whether word repetitions fall into the normal disfluency category or that of incipient stuttering (Bloodstein, 1987). What is known is that word repetitions frequently appear in both the speech of normally speaking children and incipient stutterers. The frequency and type of word repetitions and the extent to which they occur over other disfluency types seems to influence their categorization as normal or disordered. Yairi (1988) looked at eight disfluency types in 23 preschool-aged stutterers during a 2-year period. Part word repetitions, single syllable word repetitions, disrhythmic phonations, and tense pauses were the four of the eight disfluency types to be labeled the 
"Stuttering Index." In other words, these were the disfluency types most likely to be high risk indicators of incipient stuttering. Phrase repetitions, multisyllable word repetitions, interjections, and revision-incomplete phrases made up the balance of the disfluency types observed, all included as nonrisk or low-risk indicators. By including single syllable word repetitions in the stuttering Index Yairi clearly suggested that he considers them to be more indicative of abnormal disfluency. However, Meyers (1989) Iisted whole words as nonrisk indicators.

Pindzola and White (1986) developed a protocol for differentiating the incipient stutterer. The protocol is based on extensive review and synthesis of the literature. Perhaps as a result of the controversy surrounding word repetitions as high risk or low riskindicators of incipient stuttering, the Pindzola and white protocol places word repetitions in the "Questionable" category.

The Pindzola and White protocol looks at three diagnostic areas: (1) auditory behaviors, (2) visual evidence, and (3) historical and psychological indicators. The auditory behavior section classifies disfluencies according to one of three categories, Probably Normal, Questionable, and Probably Abnormal. For example, phrase repetitions are placed in the probably normal category, whole word repetitions in the questionable category, and part word repetitions are considered probably abnormal. The disfluencies are further considered based on several factors such as frequency of 
occurrence. A summary of the auditory behaviors can be found in Table $I$. This section of the protocol is most pertinent when comparing normal disfluency and incipient stuttering, since the auditory behaviors are the most frequently observed in both groups of speakers. 


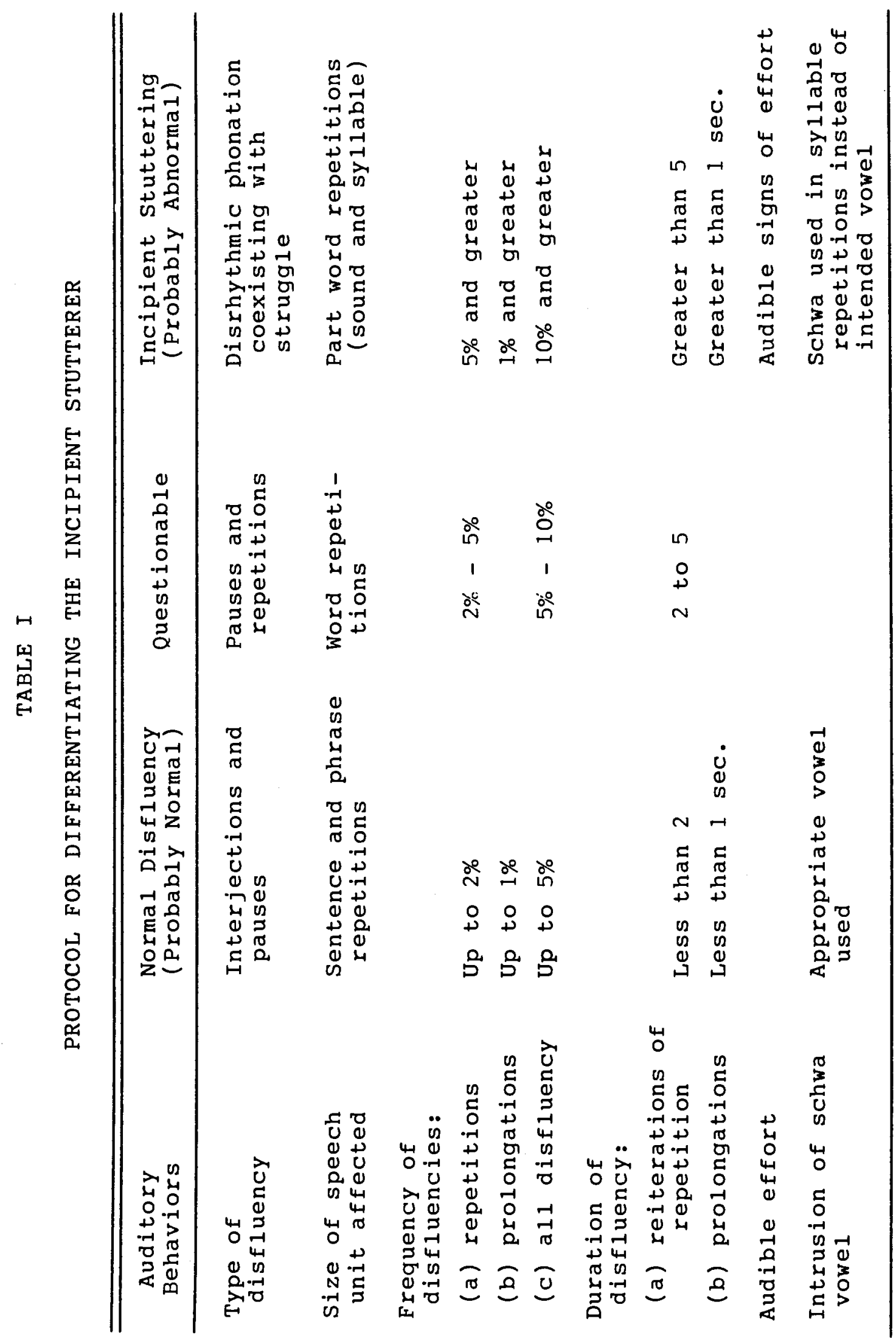


SUMMARY OF CURRENT RESEARCH

The study by Herrick (1987) found that multiple repetitions in the speech of 30- to 36-month-old children is common. Four of 20 of Herrick's subjects however, displayed one repetition or less in their speech samples. Yairi (1981) maintains that although repetitions are part of speech behavior in preschool children, not all children demonstrate them. In ranked order of occurrence, revision-incomplete phrases, single syllable word repetitions, part word repetitions, and phrase repetitions were the four most frequently occurring disfluency types.

The Arnold-Cockburn (1987) study of two groups of female subjects 30 - to 36-months-of-age and 54- to 60-monthsof-age revealed that part word repetitions were a more significant feature of speech behavior in the younger age group. She concluded that part word repetitions may be considered an indicator of speech immaturity in older children. Yairi (1982) and Starkweather (1986) concur that part word repetitions are the most immature type of speech disfluency and may signal the development of incipient stuttering in older preschool children. The findings of the Arnold-Cockburn study also showed a decrease in the incidence of repetitions with an increase in chronological age.

Yairi (1981) concluded from his study of 33 children, 2-years-old, that repetitions of short segments (one syllable or less) occurred more frequently than repetitions of longer 
segments. His findings contradict those of Davis (1939) who found that phrase repetitions occurred more frequently than word or syllable repetitions. Yairi (1981) also found that revision-incomplete phrases and interjections were dominant speech behaviors accounting for $37 \%$ of all disfluencies exhibited.

Results of the longitudinal study by Yairi (1982) of the same group of 33 children, indicated that the younger 2-year-olds' speech disfluency development was dissimilar from that of the older group of 2-year-olds. The younger group demonstrated an increase in disfluencies exhibited, especially for revisions and phrase repetitions, while the older group showed a decline particularly noted for part word repetitions and interjections. Yairi concluded that the year between 2- and 3-years-of-age is hetergeneous with respect to disfluency development and cautioned that future studies of 2- to 3-year-olds should not treat the subjects as a single age group.

The study by DeJoy and Gregory (1985) of subjects 3.5and 5-years-of-age revealed the trend for less overall disfluency with an increase in chronological age with the exception of interjections showing a slight decline and tense pauses which showed a slightly higher incidence in the older age group. In both age groups the rank order for disfluencies exhibited were as follows: revision-incomplete phrases, tense pauses, interjections, word repetitions, phrase repetitions, and disrhythmic phonations. 
The studies of Wexler (1982) and Wexler and Mysak (1982) found that revision-incomplete phrases and interjections had the highest incidence of all disfluency types in the 2-, 4-, and 6-year-old males in neutral and stress situations followed by tense pauses and word repetitions. The Wexler and Mysak data confirm the trend for a decrease in disfluency with an increase in chronological age.

Contrary to the previously reported studies, PaguiaChristianson's (1987) 5-year-old subjects demonstrated a higher incidence for total disfluencies than did the 3.5year-old group. The 5-year-old group demonstrated a higher frequency of interjections and revision-incomplete phrases while the younger children had a higher incidence of part word, word, and phrase repetitions. Interjections, revision-incomplete phrases, word repetitions, and phrase repetitions were the most dominant disfluency types in both groups of subjects.

A review of the literature revealed that while no clear-cut developmental sequences have been established, several consistent patterns have emerged regarding disfluency development. First, there appears to be the trend for less overall disfluency with an increase in chronological age. Second, part word repetitions have a higher incidence in the younger subjects and decrease with chronological age. Third, revision-incomplete phrases and interjections are the two most frequently occurring types of disfluencies exhibited in the preschool-aged subjects followed by word repetitions 
(probably single syllable word repetitions). The high incidence of tense pauses in the DeJoy and Gregory (1985) study does not coincide with the results of the other studies using subjects of the same age. However, tense pauses and interjections are frequently observed in the speech of normal adult speakers and may be considered a normal phenomenon of disfluency development. Finally, there appears to be a high degree of variability in disfluent speech behavior in normal preschool subjects particularly among the 2-year-olds who vary not only from study to study, but in the same group of children over time. 
CHAPTER III

\author{
METHODS
}

\title{
SUBJECTS
}

Fifteen males ranging in age from 44- to 49-months participated as subjects for this study. The subjects were drawn from the 20 male subjects who participated in the original Herrick (1987) study. Parents of 15 of the 20 subjects were able to be contacted or consented to participate in this longitudinal study.

All 15 subjects met selection criteria set forth in the Herrick study. These criteria included:

1. A permission form signed by a parent or primary caregiver.

2. Speech intelligibility of at least $75 \%$.

3. A minimum average of $2-1 / 2$ words per utterance.

4. An ability to attend to one or two low-stress tasks in 15 minutes.

5. No history of chronic middle ear infection or known hearing handicap.

6. No known neurological impairment, mental, or physical handicap.

7. No prior intervention or counseling for stuttering.

8. English was spoken as the primary language in the home. 
Additional selection criteria for the present study included:

1. A permission form signed by the parent or primary caregiver.

2. No intervention or counseling for stuttering since the subject's participation in the previous study.

3. Passed a hearing screen for the better ear at $25 \mathrm{db}$ HL.

Hearing screening was not provided for Herrick's subjects in the 1987 study due to their young ages and inability to attend to the hearing screening task. All subjects were assumed to have hearing within normal limits at the time of the previous study based on parent information.

\section{SUBJECT ELIGIBILITY PROCEDURES}

Each parent or primary caregiver was contacted by telephone regarding the purpose of this longitudinal study and to seek confirmation of their willingness to have their child participate again. Each parent was sent a recruitment letter (see Appendix A) and completed a permission form and questionnaire (see Appendix $B$ ) regarding the child's development since his participation in the previous study. The permission form was returned to the investigator on the day of the videotaping session. 


\section{SPEECH SAMPLE PROCEDURES}

In keeping with the design of the Herrick (1987) study, each subject was videotaped for 15 minutes interacting with the investigator in a clinic room at the Portland State University (PSU) Speech and Hearing Clinic. The clinic room has a one-way mirror and sound amplification system. The video equipment, a Panasonic Single Camera Recording System, was set up behind the one-way mirror in an adjacent control room. The speech sample was videotaped by a graduate student in the Speech and Hearing Sciences Program.

A standard set of toys, open-ended questions, parallel talk, verbal prompts, and free play were employed to elicit spontaneous samples of speech and to increase the uniformity of the task (see Appendix $C$ ).

\section{SCORING PROCEDURES}

A 300-word sample was transcribed verbatim from the video recordings for each subject by this investigator (see Appendix D for Rules for Counting Words). Each sample was analyzed and coded for specific disfluency types: part word repetitions including (a) sound repetitions, and (b) syllable repetitions; (c) monosyllabic word repetitions; (d) polysyllabic word repetitions; (e) phrase repetitions;

(f) revision-incomplete phrases; (g) interjections; (h) disrhythmic phonations; and (i) tense pauses. (See Appendix E for Identifying Disfluencies and Appendix $F$ for Coding Symbols.) 


\section{RELIABILITY}

Speech samples for each subject were assigned a number to identify them. From the 15 speech samples, 5 samples were randomly selected through the use of random order tables. A graduate student in the PSU Speech and Hearing Sciences Program then extracted utterance numbers 10 through 19 from each of the 5 samples and formed them into content transcripts (see Appendix G for Instructions for Selection of Content Transcripts). A content transcript provides the basic information of an utterance exhibited by the child and deletes any type of disfluency.

The disfluencies omitted from the content transcripts were then identified and coded by the investigator and two other trained graduate students in the speech and Hearing Sciences Program. (See Appendix $H$ for Instructions to Reliability Judges.)

In order to evaluate interjudge agreement, a percentage of agreement per utterance was computed. Interjudge agreements were as follows: Judges $A$ and $B--91 \%$; Judges $A$ and C-94\%; and Judges B and C--88\%. Samples were evaluated one week later and compared to the previous results for Intrajudge agreements, which were as follows: Judge A--100\%; Judge $\mathrm{B}--96 \%$; and Judge $\mathrm{C}--100 \%$.

\section{DATA ANALYSIS}

Sound repetitions, syllable repetitions, single syllable word repetitions, multisyllable word repetitions, phrase 
repetitions, revision-incomplete phrases, interjections, disrhythmic phonations, and tense pauses were identified and tabulated for each subject's speech sample. The mean and standard deviation of each disfluency type was computed as well as the mean total of frequency of occurrence of all disfluency types. To determine if the frequency of occurrence of disfluencies change over a 12 - to 14 -month period in a group of normal 44- to 49-month-old children when compared to their performance at 30- to 35-months-of-age, a two-tailed t-test for dependent measures was computed for the mean scores of each disfluency type and for the mean total of all disfluencies. Descriptive statistics were applied to determine how the rank order of specific types of disfluencies compared over time. The Spearman Rank-Order Correlation (rho) was used to evaluate how the rank order of individual children with regard to degree of disfluency compared over time. 
CHAPTER IV

RESULTS AND DISCUSSION

\section{RESULTS}

The purpose of this study was to compare current types and amounts of disfluencies in 44- to 49-month-old children to their disfluency types and amounts when they were 30 - to 35-months-of-age. Individual speech samples were obtained from the 15 male subjects. The speech samples were videotyped, transcribed, and analyzed for the following nine types of disfluencies: (1) sound repetitions, (2) syllable repetitions, (3) single syllable word repetitions, (4) multisyllable word repetitions, (5) phrase repetitions, (6) revision-incomplete phrases, (7) interjections, (8) disrhythmic phonations, and (9) tense pauses. These data will be reported in order to answer the questions posed in this investigation. Further, it needs to be noted that Herrick's (1987) data were recalculated (minus 5 subjects) in order to make comparisons between the two studies.

\section{Questions}

1. Does the frequency of occurrence of disfluencies change over a 12 - to 14 -month period in a group of normal 44- to 49-month-old children when compared to their performance at 30 - to 35 -months-of-age? 
A two-tailed $\underline{t}$-test for dependent measures was computed to compare the mean scores of each disfluency type from the Herrick (1987) revised data with the corresponding mean scores from the present study. The data revealed that syllable repetitions were the only type to change significantly at the .05 alpha level. They decreased from the previous year. Table II presents the mean, standard deviation, and $\underline{t}$-score of all disfluencies.

TABLE II

RESULTS OF A TWO-TAILED $t$-TEST FOR DEPENDENT MEASURES COMPARING THE MEANS OF FREQUENCIES OF OCCURRENCE FOR DISFLUENCY TYPES IN 1987 AND 1988

\begin{tabular}{l|rr|rr|rr}
\hline \multirow{2}{*}{$\begin{array}{l}\text { Disfluency } \\
\text { Types }\end{array}$} & \multicolumn{2}{|c|}{1987} & \multicolumn{2}{|c|}{1988} & \multirow{2}{*}{ df } & t-score \\
\cline { 2 - 5 } Sd R & Mean & SD & \multicolumn{2}{|c}{ Mean } & SD & \\
SY R & .71 & 1.13 & .27 & .42 & 14 & 1.375 \\
SSWR & .31 & .38 & .04 & .17 & 14 & $2.305 *$ \\
MSWR & 1.33 & 1.23 & 1.24 & .80 & 14 & .349 \\
Ph R & .02 & .09 & 0 & 0 & 14 & .999 \\
I & .42 & .42 & .46 & .30 & 14 & -.326 \\
RIP & .88 & .97 & 1.89 & 1.87 & 14 & -1.987 \\
DP & 1.31 & .73 & 1.46 & 1.30 & 14 & -.413 \\
TP & .09 & .20 & .31 & .44 & 14 & -1.729 \\
& .02 & .09 & .27 & .52 & 14 & -1.747 \\
\hline
\end{tabular}

$\mathrm{N}=15$

* Significant at $\mathrm{p} \leq .05$. 
2. How does the rank order of specific types of disfluencies compare over time?

A rank order of disfluency types of the present study are shown in Table III.

TABLE III

RANK ORDER OF ALL DISFLUENCY TYPES EXHIBITED IN 1988 WITH THE CORRESPONDING 1987 RANKINGS

\begin{tabular}{ccc}
\hline \hline 1988 & Most to Least Frequently Occurring & 1987 \\
\hline 1 & Interjections & 3 \\
2 & Revision-incomplete phrases & 2 \\
3 & Single syllable word repetitions & 1 \\
4 & Phrase repetitions & 5 \\
5 & Disrhythmic phonations & 7 \\
6 & Sound repetitions & 4 \\
7 & Tense pauses & 8 \\
8 & Syllable repetitions & 6 \\
9 & Multisyliable word repetitions & 9 \\
\hline
\end{tabular}

Single syllable word repetitions, revision-incomplete phrases, and interjections retained the top three positions in rank, although in different order, from 1987 to 1988. Single syllable word repetitions, ranking first in 1987 , dropped to third position in 1988. Phrase repetitions retained its ranking of second position. Interjections in third position in 1987, moved up to first position in the present study. Sound repetitions in fourth position in 1987 , 
aropped to sixth position in 1988 . Phrase repetitions rose from its position of fifth place in 1987 to fourth in 1988 . In sixth place in 1987 , syllable repetitions decreased to eighth place in 1988. Disrhythmic phonations, which ranked seventh the previous year, rose to fifth position in 1988 . Tense pauses rose slightly from a ranking of eighth to seventh over a one-year period. Multisyllable word repetitions maintained the lowest position in rank, ninth, for both testing periods.

The greatest increase for mean frequency which moved a disfluency type in ranking was for interjections, rising slightly more than 1.0 per 100 words, for a mean of 1.89 . Multisyliable word repetitions demonstrated the least amount of change over a one-year period with a mean frequency of .02 in 1987 to 0 in 1988 .

3. How does the rank order of the individual children with regard to degree of disfluency compare over time?

The Spearman Rank-order Correlation (rho) was computed to determine the relationship between each child's current fluency rank order and the rank order of the previous year. Table IV shows the rank comparison of the individual subjects, with regard to degree of total disfluency for the revised Herrick (1987) data and the present study. Rho was determined to be .447 , a somewhat moderate association between how each child ranked in 1987 and then again in 1988 . To determine the significance of rho, a two-tailed $t$-test was 
used. Results indicated that at the .05 level of probability, rho was not statistically significant.

\section{TABLE IV}

RESULTS OF THE SPEARMAN RANK-ORDERED CORRELATION ( $\mathrm{rho \text {) }}$ FOR HOW EACH CHILD RANKED IN 1987 AND 1988 AND THEIR OVERALL DISFLUENCY MEAN

Most to Least Disfluent Subjects

\begin{tabular}{cccccc}
\hline Subjects & 1987 & Overal1 Mean & 1988 & Overal1 Mean & $D^{*}$ \\
\hline A & 1 & 15.65 & 1 & 11.98 & 0 \\
B & 2 & 8.33 & 9 & 4.99 & 7 \\
C & 3 & 6.66 & 4 & 8.98 & 1 \\
D & 4 & 6.31 & 14 & 1.32 & 10 \\
E & 5 & 6.00 & 7 & 5.99 & 2 \\
F & 6 & 5.50 & 2 & 11.31 & 4 \\
G & 7 & 5.0 & 3 & 9.99 & 4 \\
H & 8 & 4.50 & 11 & 3.00 & 3 \\
I & 9 & 3.97 & 6 & 6.98 & 3 \\
J & 10 & 3.64 & 8 & 5.96 & 2 \\
K & 11 & 3.33 & 13 & 2.65 & 2 \\
L & 12 & 3.32 & 15 & .99 & 3 \\
M & 13 & 2.49 & 5 & 7.32 & 8 \\
N & 14 & 1.00 & 10 & 4.00 & 4 \\
O & 15 & .66 & 12 & 2.66 & 3 \\
\hline
\end{tabular}

rho $=.447$

* Difference between rankings. 


\section{DISCUSSION}

Only one longitudinal study to date has been reported on disfluencies in normal preschool children. Yairi (1981, 1982) maintained that incomplete conclusions are drawn about the developmental sequences of disfluency when studies focus on subjects representing different age groups. The studies fail to describe the short term variations in the same subjects' speech and the developmental changes that occur over time.

The following discussion will examine comparisons of disfluency occurrence, rank order of disfluencies compared, rank order patterns of individual subjects, and comparison of trends.

\section{Comparisons of Disfluency}

\section{Occurrence}

In the present study it was found that syllable repetitions (part word) was the only disfluency type to change significantly in any direction, by decreasing over time. Although not statistically significant, changes were observed for the remaining types of disfluencies.

Observation and tabulation of repetitions is a traditional approach to gathering normative data on preschool-aged children (Davis, 1939). Starkweather (1986) hypothesized that repetitions are characteristic of normal disfluency development in preschool children, but reflect immaturity in fluency development in older children. Specifically, he 
stated, "False starts are somewhat immature, repetitions are quite immature, and part word repetitions are very immature" (p. 75$)$.

The results of the present study revealed that part word repetitions and single syllable and multisyllable word repetitions all decreased in frequency from 1987 when the subjects were $30-$ to 35 -months-of-age to 1988 when the subjects were 44 - to 49 -months old. Phrase repetitions, on the other hand, remained nearly static over time, with a mean of .42 in 1987 and .46 in 1988. The findings of the current study are consistent then with several cross-sectional studies which found a decrease of repetitions with advancing age .

The overall results from the longitudinal study by Yairi (1982) also revealed a decrease in part word repetitions, and single syllable and multisyllable repetitions over a one-year period. Phrase repetitions remained constant from the first testing period to the last, consistent with the results of the present investigation. As was previously reported, different results were yielded when comparing each of Yairi's subgroups independently. In the younger subgroup, part word repetitions, single syllable word repetitions, and phrase repetitions all increased in frequency over time. Conversely, the older 2-year-old group demonstrated a decrease for all repetition type disfluencies. The subjects of the present study, who were also "older 2-year-olds" at the time of the Herrick (1987) investigation, performed 
similarly to Subgroup II in the Yairi (1982) study in this regard.

In the DeJoy and Gregory (1985) cross-sectional study, subjects 3.5-years-of-age had, in general, higher rates of repetition than did the subjects of approximately the same age in the present study. In particular, phrase repetitions were reported at 1.16 for their 3.5-year-olds, and .46 for the 3.8-year-old subjects of the current investigation. The 5-year-old subjects in their study did approach the overall repetition level of this current study. Reasurringly, the mean of word repetitions decreased from 1.37 for the 3.5-year-old subjects in their study, to 1.24 for the 3.8-year-old subjects of the present study, to .78 for the 5-year-olds. This finding is not unexpected with an increase in chronological age in normal speaking preschool children according to starkweather (1986). The differences in frequency of occurrence were less evident from 4- to 6years-of-age, which would indicate value in following these subjects further.

Arnold-Cockburn's (1987) subjects 30- to 36-months-ofage demonstrated significantly more part word repetitions (1.50) than did the subjects 54 - to 60-months-of-age (.63). Similarly, in the present study, subjects 30- to 35-monthsof-age had a mean of 1.02 for part word repetitions (sound and syllable combined) and .46 one year later. Word repetitions in Arnold-Cockburn's study were nearly equal in her two groups of subjects, with a mean of 1.30 in the younger 
group and 1.37 in the older group. Although with similar means, the results from the present investigation demonstrated fewer word repetitions (single syllable and multisyllable combined) over a one-year period with a mean of 1.35 in 1987 to 1.24 in 1988 .

Whereas most repetition disfluencies decreased with advancing age over a one-year period in the present study, all other disfluency types increased. Again, the changes were not statistically significant but interesting to compare to several contemporary studies.

In the present study increases were noted for the following disfluency means over a one-year period: interjections rose from .88 in 1987 to 1.89 in 1988; revisionincomplete phrases moved from 1.30 to 1.46 ; disrhythmic phonations, at .09 in 1987, were at .31 in 1988; and tense pauses increased from .09 to .27 .

The findings of the present study are most consistent with the Paguia-Christianson (1987) cross-sectional results of increases in disfluencies, other than repetitions, with advancing age. In her study, increases were revealed for interjections, revision-incomplete phrases, and disrhythmic phonations from 3- to 5-years-of-age. Tense pauses, however, were equal in both groups in her study.

Conversely, Yairi's (1982) longitudinal data indicated decreases for interjections, disrhythmic phonations, and tense pauses when looking at the overall results of the group. Frequency for revisions remained the same. It seems 
noteworthy that when looking at the younger subgroup exclusively, revisions, disrhythmic phonations, and tense pauses all increased in frequency over the one-year period.

Arnold-Cockburn's (1987) subjects, 30- to 36-months and 54- to 60-months-of-age, demonstrated the same frequency means for revision-incomplete phrases, the only nonrepetition-type disfluency tabulated in her study.

The Wexler and Mysak (1982) cross-sectional data does not confirm the trend found in the present longitudinal investigation in disfluency types other than repetitions from 2- to 4-years-of-age nor from 4- to 6-years old. Similarly, the results from the DeJoy and Gregory (1985) study do not support increases for nonrepetition types of disfluencies in their subjects from 3.5- to 5-years-old.

In this discussion, classification of disfluencies has been made along repetition-nonrepetition lines. An alternative method of arranging the data from the present study, is to distinguish high risk disfluencies from low risk or nonrisk ones. In the present study, the total of low risk disfluency types (phrase repetitions, interjections, and revision-incomplete phrases) occurred more frequently than the total of high risk types (part word repetitions, single syllable word repetitions, disrhythmic phonations, and tense pauses), with means of 3.81 and 2.13 respectively. The previous year the differences between low risk and high risk disfluencies were minimal with a mean of 2.63 for low risk and 2.46 for high risk disfluencies. That high risk 
disfluencies decreased over a one-year period lends support to Yairi's (1982) observation that even during times of increase in total disfluency, part word repetitions tend to decrease with maturation. The greater increase between high risk and low risk indicators, with low risk (or nonrisk) occurring more frequently, is what a clinician would hope to find with normal fluency development.

Having looked at disfluency types in two different ways, it is necessary to look at disfluencies unrelated to types, i.e., total disfluencies over time.

For overall frequency of occurrence of all disfluency types, the findings of the current study did not support a decrease of disfluency with an increase in chronological age. To the contrary, these findings are more similar to those of Paguia-Christianson (1987) whose study was the only one of those reviewed to show an increase of disfluency from 3- to 5-years-of-age, though not significantly in either study. It should be mentioned that while the mean for disfluencies for the entire group of subjects in the Yairi (1982) longitudinal study decreased over a one-year period, the 13 younger subjects demonstrated an increase in total disfluency.

Additionally, the results of the present investigation with regard to the mean frequency of occurrence for all disfluencies at 5.94, up from 5.09 the previous year, was closest to the results of the 3-year-olds in the PaguiaChristianson (1987) study at 5.47. Her 5-year-olds had a mean of 6.87. The Wexler and Mysak (1982) data showed higher 
rates of disfluency per 100 words at the 2-, 4-, and 6-yearold levels; $14.56,9.10$, and 9.08 respectively. Similarly, DeJoy and Gregory's (1985) findings for 3.5-year-olds were 11.40 per 100 words, and 9.30 for the 5-year-olds. Yairi's (1981) data revealed disfluency means of 6.49 and his followup (1982) results were reported at 4.09 for the same subjects one year later. Once again, the younger subgroup did not follow the trends for the overall group with respect to decreasing disfluency with advancing age. The younger groups' overall mean rose over the one-year period from 3.97 to 6.90. One should not overlook the central tendency of these various studies. The means for both test periods in the present study are clearly lodged in the middle range when considering all other studies and their various means.

\section{Rank order of Disfluencies}

\section{Compared}

In addressing how the rank order of disfluencies compared over time, the present study resulted in the following frequency order for the nine types from most to least frequent: interjections, revision-incomplete phrases, single syllable word repetitions, phrase repetitions, disrhythmic phonations, sound repetitions, tense pauses, syllable repetitions, and multisyllable word repetitions. Interjections, revision-incomplete phrases, and single syllable word repetitions retained the top three positions in rank, although not in exact order, from the previous year. Phrase repetitions with its ranking of fourth position in the present study, 
was in fifth place in 1987, however, the frequency of occurrence was nearly the same for both years. Further changes in rank have been presented in the Results section and need not be reiterated here.

To the extent that rank order comparisons can be made to other studies, the rank order for the disfluency types in the present study are closest to the findngs of PaguiaChristianson (1987) for 5-year-old subjects. In the 5-yearold group, interjections ranked first followed by revisionincomplete phrases, word repetitions, and phrase repetitions. Even the 3-year-old group in her study had the same four disfluency types in the top four positions in rank, although not in the same order.

That Arnold-Cockburn (1987) investigated only three disfluency types and other studies (DeJoy and Gregory, 1985; Paguia-Christianson, 1987; Wexler and Mysak, 1982; Yairi, 1981, 1982) chose to report certain disfluency types as single categories has already been shown to make direct comparisons more difficult. Differences aside, interjections and revisionincomplete phrases are usually found in two of the top three positions in rank when looking at all studies. Word repetitions (most likely single syllable words) occupies one of the top three positions in rank in the Herrick (1987) revised data, Yairi (1981, 1982) studies, Paguia-Christianson (1987) results for 5-year-olds and in the present study. Tense pauses occur in one of the top three positions in rank in the DeJoy and Gregory (1985) study for both 3- and 5-year-olds, 
as well as in the Wexler and Mysak (1982) data for 4- and 6year-olds, but in the present study, tense pauses ranked only seventh. Phrase repetitions is found in one of the top three positions in rank in the Paguia-Christianson (1987) data for 3-year-olds, and for 2-year-olds in the Wexler and Mysak (1982) study. Phrase repetitions is in fourth position in the current investigation.

Disrhythmic phonations is consistently found in one of the last three positions in rank in the revised Herrick (1987) data, Yairi $(1981,1982)$ investigations, DeJoy and Gregory (1985) data for both 3- and 5-year-olds, PaguiaChristianson (1987) data for both 3- and 5-year-olds, and in the Wexler and Mysak (1982) results for all age groups, 2,4 , and 6 . In the current study, disrhythmic phonations was ranked fifth out of nine disfluencies, up from its ranking of seventh the previous year. The frequency however, at .31 in the present study and .09 in 1987, was not sufficient to cause alarm (Pindzola and White, 1986).

Eight subjects in the present study became more disfluent, marked primarily by an increase in revisionincomplete phrases and interjections. Six subjects became less disfluent, marked by decreases in sound repetitions, single syllable word repetitions, and revision-incomplete phrases. One subject maintained the same incidence level even though the nature of the disfluencies changed slightly. 
Comparison of Trends

A comparison of the disfluency trends to emerge from the current literature and the present study show some differences and similarities. First, the present study did not support a decrease for overall disfluency with advancing age. The current investigation did show an overall decrease in repetition disfluencies. Interjections, revision-incomplete phrases, disrhythmic phonations, and tense pauses, however, all increased over a one-year period. Of all the studies reviewed, only the Paguia-Christianson (1987) findings were similar to those of the present investigation.

Second, the analysis of data from the current study supports the trend for a decrease of part word repetitions with an increase of chronological age. The revised Herrick (1987) data revealed the mean of sound repetitions at .71 and syllable repetitions at .31 per 100 words. The results of the same children one year later revealed a mean of .27 for sound repetitions and .04 for syllable repetitions.

Third, revision-incomplete phrases and interjections were the two most frequently occurring disfluency types to occur in the present study, consistent with the trends of the current literature.

Finally, the results of the present study support Yairi's (1982) longitudinal data from 2-year-old children followed over a one-year period. Yairi found that a high degree of variability exists in patterns of disfluency. Not only is this evident among the subjects of the present study 
but is also observed for children of the same and different ages when looking cross-sectionally at the other studies. 
CHAPTER V

SUMMARY AND IMPLICATIONS

SUMMARY

The process of differentially diagnosing a child who is experiencing temporary normal disfluency from one who is beginning to stutter could be made objective by the establishment of normative data on fluency development. To date, there are no standardized norms on the development of fluency in children. Current investigations have contributed greatly to expectations of certain types and amounts of disfluencies in preschool-age children. Most of the research, however, has focused on observing children at discrete age levels from 2- to 7-years-of-age. Only one longitudinal study to date has been reported. Additional longitudinal data of preschool-aged children would benefit the establishment of normative data. Observing the same children over time helps to expose the subtleties that could be missed when looking only at specific age levels. The present study sought to contribute to the investigation of normal childhood disfluency by comparing various types and amounts of disfluencies in 44- to 49-month-old children to the results of the same group of children when they were 30- to 35-months-ofage. 
Fifteen male subjects ranging in age from 44 to 49 months participated as subjects. The 15 subjects were drawn from the 20 subjects who participated in the original Herrick (1987) study. Subjects were videotaped for 15 minutes during free play with toys and during conversation with the investigator. Speech samples were analyzed for the following nine disfluency types: sound repetitions, syllable repetitions, single syllable word repetitions, multisyllable word repetitions, phrase repetitions, revision-incomplete phrases, interjections, disrhythmic phonations, and tense pauses.

The analysis of data revealed that syllable repetitions were the single disfluency type to change significantly, by decreasing, over a 12- to 14-month period, in a group of normal 44- to 49-month-old children. The total of low risk disfluency types (interjections, revision-incomplete phrases, phrase repetitions, and multisyllable word repetitions) occurred more frequently than did the total of the high risk disfluency types (sound and syllable repetitions, single syllable word repetitions, disrhythmic phonations, and tense pauses). The rank order of disfluencies changed slightly over a one-year period. The rank order for the individual children revealed a somewhat moderate association between how they ranked in 1987 and in 1988, although not at a statistically significant level of confidence.

The findings of the present study did not support the trend found in the literature for a decrease in overall 
disfluency with an increase in chronological age. The total of repetition type disfluencies (sound and syllable repetitions, single syllable and multisyllable word repetitions) all decreased in frequency (phrase repetitions remained nearly the same). Interjections, revision-incomplete phrases, disrhythmic phonations, and tense pauses, however, all increased in frequency. The findings of the current study are consistent with recent studies which support a decrease of part word repetitions with advancing age. Also consistent with most of the related studies is the finding that revision-incomplete phrases and interjections are the most frequently occurring disfluency types in normal speaking children. Finally, the findings of the present study support the longitudinal data from Yairi's (1982) investigation of 2-year-old children that a high degree of variability exists in patterns of disfluency from one year to the next.

\section{IMPLICATIONS}

\section{Clinical}

The results of this longitudinal study provide additional information on normal disfluency in the speech of preschool children. In particular, the findings suggest the following regarding differential diagnosis: (a) the range of variability of disfluencies in the same child over time should be considered; (b) the decrease of part word repetitions over a one-year period in the present study supports starkweather's (1986) hypothesis that they have diagnostic value as 
indicators of abnormal disfluency with advancing age in preschool children; and (c) less emphasis should be placed on word repetitions (in particular single syllable word repetitions) as high risk indicators of incipient stuttering.

\section{$\underline{\text { Research }}$}

The small number of children used in this study limits the extent to which inferences can be made based on these longitudinal findings. Additional longitudinal studies, following a larger number of 2-year-olds, are needed to determine if a decrease for overall disfluency with advancing age is indicative of normal patterns of fluency development. The reverse of this trend was found in the present study.

More research is needed to determine if single syllable word repetitions and multisyllable word repetitions should be combined into a single disfluency type, word repetitions, for purposes of observation. Based on the results of the present study, multisyllable words appear to occur infrequently in the speech of normally speaking preschool-aged children, and their tabulation as a separate disfluency type seems unwarranted.

Continued research is also needed regarding the disfluency category of word repetitions to determine if they should be considered a high risk indicator of incipient stuttering. The literature is still undecided in this regard.

It would be interesting to compare disfluency types and amounts in a longitudinal study of children identified as stutterers and a matched group of normal speakers to 
determine similarities and differences over time under the same conditions.

Additional longitudinal studies with larger groups of subjects and for a longer period of time are needed to determine disfluency trends. Finally, a larger number of subjects could possibly yield statistical differences which were not observed in the present study with regard to disfluency types and amounts. 
Adams, M. (1980). The young stutterer: diagnosis, treatment, and assessment of progress. In W. H. Perkins (ed.), Strategies in stuttering therapy. New York: Thime-stratton, Inc.

Arnold-Cockburn, S. (1987). Discontinuities in normal 30 to 36 month $01 d$, and 54 to 60 month old female children. Masters thesis, Portland State University.

Bloodstein, 0. (1974). The rules of early stuttering. Journal of Speech and Hearing Disorders, 39, 379-394.

(1987). A handbook on stuttering. 4th ed. Chicago, IL: The National Easter Seal Society.

Branscom, M., Hughes, J., and Oxtoby, E. (1955). Studies of nonfluency in the speech of preschool children. In $W$. Johnson (ed.), stuttering in children and adults. Minneapolis: University of Minnesota Press.

Davis, D. (1939). The relation of repetitions in the speech of young children to certain measures of language maturity and situational factors. Journal of Speech Disorders, 4, 303-318.

DeJoy, D. and Gregory, H. (1985). The relationship between age and frequency of disfluency in preschool children. Journal of Fluency Disorders, 10, 107-122.

Herrick, S. (1987). Repetitions in the speech of normal 2-year-old males. Masters thesis, Portland state University.

Johnson, W. (1955). Stuttering in children and adults. Minneapolis: University of Minnesota Press.

(1959). The onset of stuttering: research and findings. Minneapolis: University of Minnesota Press.

(1961. Measurements of oral reading and speaking rate and disfluency of adult male and female stutterers. Journal of Speech and Hearing Disorders Monograph supplement, $7,1-20$. 
Meyers, S. (1989). Nonfluencies of preschool stutterers and conversational partners: observing reciprocal relationships. Journal of Speech and Hearing Disorders, $54,106-112$.

Paguia-Christianson, P. (1987). Disfluencies in normal 3 and 5 year old children. Masters thesis, Portland State University.

Perkins, W. (1983). Onset of stuttering: the case of the missing block. In D. Prins and R. J. Ingham (eds.), Treatment of stuttering in early childhood: methods and issues. Houston, TX: College-Hill Press.

Pindzola, R. and White, D. (1986). A protocol for differentiating the incipient stutterer. Language, speech and Hearing Services in Schools, $17,1,2-15$.

Riley, G. (1972). A stuttering severity instrument for children and adults. Journal of Speech and Hearing Disorders, $37,314-320$.

Sheehan, J. (1975). Conflict theory and avoidance therapy. In J. Eisenson (ed.), Stuttering: a second symposium. New York: Harper and Row.

Starkweather, C. (1986). Development of fluency in normal children. In stuttering Therapy. Memphis, TN:

Speech Foundation of America.

Van Riper, C. (1971). The nature of stuttering. Englewood Cliffs, NJ: Prentice-Hall, Inc.

(1973). The treatment of stuttering. Englewood Cliffs; NJ: Prentice-Hall, Inc.

Wexler, K. (1982). Developmental disfluency in 2, 4, and 6 year old boys in neutral and stress situations.

Journal of Speech and Hearing Research, 25, 229-234.

Wexler, K. and Mysak, E. (1982). Disfluency characteristics of 2, 4, and 6 year old males. Journal of Fluency Disorders. $7,37-46$.

Williams, D., Silverman, F., and Kools, J. (1968). Disfluency behavior of elementary school stutterers and nonstutterers: the adaptation effect. Journal of Speech and Hearing Research, 11, 622-630.

Wingate, M. (1964). A standard definition of stuttering. Journal of Speech and Hearing Disorders, $29,484-489$.

(1987). Fluency and disfluency: illusion and identification. Journal of Fluency Disorders, $12,79-$ 101 . 
Wood, B. (1976). Children and communication: verbal and nonverbal language development. Englewood Cliffs, $\mathrm{N} J$ : Prentice-Hall, Inc.

Yairi, E. (1981). Disfluencies of normally speaking twoyear-old children. Journal of Speech and Hearing Research, 24, 490-495.

(1982). Longitudinal studies of disfluencies in two-year-old children. Journal of Speech and Hearing Research. 25, 145-154.

Yairi, E. and Lewis, B. (1984). Disfluencies at the onset of stuttering. Journal of Speech and Hearing Research, $27,145-154$

Yairi, E. (February 24, 1988). Personal communication. 


\section{APPENDIX A}

\section{RECRUITMENT LETTER}

Dear

I am a graduate student at Portland State University in the speech and Hearing sciences program, and I am conducting a longitudinal study of disfluencies in preschool children's speech. As you may recall, your child participated in Stephanie Herrick's study last year. I would like to follow-up on how your child's speech may have changed since last year.

The way in which your child participates in this study will be similar to the way in which he previously participated. I would like to videotape your child during $15 \mathrm{~min}-$ utes of play and conversation with me at Portland state University. Prior to the videotaping session, I would like to screen your child's hearing to insure that it is within the normal range. This will take about five minutes.

Your child's name will not be used in reporting the results of this study and the videotape will be used only for research purposes by authorized university personnel. You may withdraw your child from this study at any time without penalty.

I will call you to set up a time for you to come in that is convenient for both you and the department. You may return the enclosed permission form to me on the day we arrange for you and your child to come in. Please call me at home if you have any questions (692-0539). I greatly appreciate your cooperation.

If you have any problems as a result of your child's participation in this study, please contact the secretary of the Human Subjects Research and Review Committee, Office of Grants and Contracts, 303 Cramer Hal1, Portland State University, 464-3417.

I look forward to meeting with you.

Sincerely, 


\section{APPENDIX B}

\section{CONSENT FORM}

CHILD'S NAME: NICKNAME :

BIRTHDATE : $A G E$ :

1. Since participating in this study in 1987 has your child been diagnosed as demonstrating any of the following:

developmental delay neurological impairment hearing loss mental retardation orthopedic or physical handicap $\begin{array}{ll}\text { yes no no } & \text { no } \\ \text { yes } & \text { no } \\ \text { yes } & \text { no } \\ \text { yes } & \text { no }\end{array}$

2. Has your child received speech therapy for stuttering? yes no

I hereby give my permission for my child, to participate in this study. My child may attend a videotaping session at an agreed upon date and time.

I understand I may withdraw my permission at any time during this study without penalty. 


\section{APPENDIX C}

\section{LIST OF STIMULI}

\section{TOYS}

1 toy watch

2 cars

1 telephone

2 medium-sized rubber toys (Gumby and Pokey)

1 wind-up toy

3 puppets

2 dolis

1 doll comb

Fisher-Price Farm Set with extra animals

tea set

\section{SAMPLE QUESTIONS}

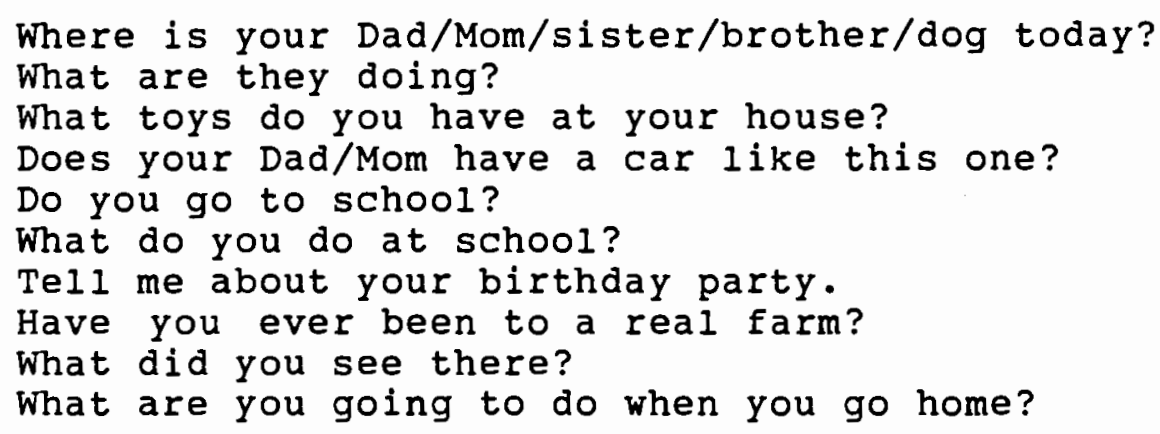

\section{SAMPLE VERBAL PROMPTS}

You do/did?

Tell me about it.

Why?

Hmmm.

Oh.

Pretending to talk on telephone

Pretending to drink coffee

Modeling puppetry

I wonder if the animals are hungry/sleepy 


\section{APPENDIX D}

\section{RULES FOR CALCULATING WORD SAMPLES}

1. Contractions of a verb form and "not" such as "won't" and "can't" are counted as one word. Contractions of a noun or pronoun and a verb, such as "I' $m$ " and "they're" are also counted as one word (Branscom et al., 1955).

2. Hyphenated words which must occur together to convey thought are scored as one word, such as "teeter-totter" (Branscom et al., 1955).

3. Nonsense syllables are not counted as words.

4. Interjections, such as "ah," and "um," and extraneous words such as "well" and "you know" are not included in total word count. Interjections are referred to as "stallers" by Branscom et al. (1955).

5. For each instance of repetition, only the last complete form is included in the total word count. For example: "can-can-can" or "c-c-can" is counted as one word; "I can go, I can go" is counted as 3 words.

6. For each instance of revision-incomplete phrase, all words are included in the total word count. Part words are also counted in this instance when the production was intentionally revised. For example: "She I mean he ran away" is counted as 6 words; "You ca- you could do that" is counted as 6 words.

7. Isolated "yes" and "no" responses are deleted from the total word count to prevent inflating the speech samples with single word utterances. "Yes" or "no" followed immediately by another word or phrase, however, are retained (Yairi and Lewis, 1984).

8. Utterance segmentation should be based on terminal intonation contour, rising or falling.

9. Words that are used to initiate more than two utterances in succession and are not associated with meaningful text, are not included in the total word count. Examples: "Hey," "oh," "and." 
10. Words used to represent animal noises, such as "meow," "oink," or "buck, buck" are only included in the total word count when used within phrases. Examples:

"Buck, buck" would not be counted; "the dog says woof" would be counted. 
APPENDIX E

RULES FOR IDENTIFYING DISFLUENCIES

1. The insertion of any nonidentical remark between identical remarks cancels the repetitions. This includes words such as "yes," "no," and personal names. For example: "Put it in the wagon, no, put it in the wagon," or "We won't go down. Watch. We won't go down."

2. A phrase repetition may occur as part of one response, or may involve the repetition of a total response. For example: "What are these things, what are these things?" or "What are these, what are these things?" (Branscom et a1., 1955).

3. The calling of an individual's name over and over does not count as a repetition. For example: "Mary, Mary, Mary."

4. The absence of the definite or indefinite article does not cancel the response as a repetition, because of the difficulty of detecting it in rapid speech. For example: "You sleep in the doghouse, you sleep in doghouse" (Branscom et al., 1955).

5. A neutral vowel interjected or any interjections between two utterances of a part word repetition, word repetitions, phrase repetitions, or revision-incomplete phrases does not negate the disfluency. The neutral vowel is counted as an interjection. With or without the interjection, it is still an instance of disfluency. For example: "Are you, uh, are you going?" (Johnson, 1961).

6. Repetition of words of one syllable, such as "I" and "a" is considered word repetition rather than syllable repetition (Branscom et al, 1955).

7. Repetition of part of a contraction is considered a part word repetition. Example: "I-I-I'm."

8. Sounds made in imitation of motors, rushing water, etc., are not scored as repetitions, since the child is attempting to imitate a continuous sound (Branscom et al., 1955). 
9. Repetitions which are obviously part of a quotation are not scored as repetitions. For example: "Ba, ba, black sheep, have you any wool? Yes sir, yes sir, three bags ful1" (Branscom et a1., 1955).

10. Repetitions that are definitely self-corrections as far as they involve a change of thought or word are not counted as repetitions but as revision-incomplete phrases. For example: "Thirty......thirty-four" (Branscom et al., 1955).

11. Repetitions of either meaningful or nonsensical syllables, words, or phrases for the apparent enjoyment of rhythm are not counted as repetitions. Due to the fact that this is a subjective judgment on the part of the investigator, the context will be the deciding factor.

12. Words that are repeated for emphasis are not counted as repetitions. Example: "very, very clean" (Johnson, 1961).

13. Extraneous sounds such as "um," "er," "hm," or words such as "well" and "you know" which are produced unintentionally within the flow of speech and are not part of the phrase or sentence are identified as interjections. No matter how many times an interjection is repeated during one instance, it is only credited as one interjection. Example: "Um-um, can I go to the store?" contains only one instance of interjection while "uh, I went to the park and um-um, we saw some dogs' contains two instances of interjections.

14. Instances in which the content or grammar of a phrase or pronunciation of a word is modified are considered as revision-incomplete phrases. Example: "you go-you want to go to the store?" "My do-there's another car."

15. Audible or silent continuations of a sound or articulatory posture which interrupts the rhythmic flow of speech are considered disrhythmic phonations. Broken words, hard attacks, and sound prolongations are synonymous with disrhythmic phonations.

16. Tension existing between words, part words, and interjections is identified as tense pause. 


\section{APPENDIX F}

\section{CODING SYMBOLS}

Interjection

Sound repetition

Syllable repetition

Single syllable word repetition

Multisyllable word repetition

Phrase repetition

Revision-incomplete phrase

Disrhythmic phonation

Tense pause
I

Sd R

Sy $R$

SSWR

MSWR

$\mathrm{Ph}$ R

RIP

DP

TP 


\begin{abstract}
APPENDIX G
INSTRUCTIONS FOR SELECTION OF CONTENT TRANSCRIPTS FOR RELIABILITY TESTING
\end{abstract}

Videotapes have been made of a child and an adult interacting in a parallel play situation. The children's conversations in these videotapes have been transcribed verbatim, and these transcripts are what you will be working from. You are responsible for extracting ten utterances from each of the five transcripts you are given, and forming a content transcript for each one. A content transcript can be defined as the basic information of an utterance provided by the child, with disfluencies deleted, and without any additional words that the child did not specifically speak. There are specific guidelines that you need to follow when developing these content transcripts.

\title{
GUIDELINES:
}

1. Use utterance 10 through 19 from each of the five transcripts to form content transcripts.

2. Additional words should not be added to the utterances. Use only those words that are present in the original transcripts.

3. Some utterances will be included in their entirety in the content transcripts. This is especially true if the 
original utterances are very short and do not include any disfluencies. For example, the following utterance would be included in the content transcripts in full:
a. $\mathrm{Hi}$.
b. And those.
c. Her name is Sally.

4. Disfluencies in the original transcript should not be included in the content transcript. This includes any repetitions, interjections, revision-incomplete phrases, tense pauses, and disrythmic phonations. For example, "I-I-I am going" would be written "I am going," and "Uh, I need, uh, I need to talk," would be written "I need to ta1k."

5. In transcribing revision-incomplete phrases into content utterances, on1y the most complete form of the utterance is included. For example, "It is a ze- it is a giraffe," would be written "It is a giraffe."

6. The following words were not counted in the original language samples and should not be included in the content transcripts: unintelligible utterances; utterances including unintelligible words; single "yes" and "no" responses; isolated words used for animal noises; "oh," and "hey."

7. Any additional sounds or pulses at the beginning, middle, or end of an utterance should not be included in the content transcript. 
EXAMPLES OF ORIGINAL TRANSCRIPTION AND CORRESPONDING CONTENT TRANSCRIPTION:

Original Transcription

1. I don't know.

2. I, he, I already tell him.

3. W-w-w-where is she?

4. I think, I think she got it.

5. I have, uh, car at home.
Content Transcription

1. I don't know.

2. I already tell him.

3. Where is she?

4. I think she got it.

5. I have car at home. 


\section{APPENDIX H \\ INSTRUCTIONS TO RELIABILITY JUDGES}

\section{General Instructions}

You will be given five partially complete transcripts of ten utterances each. The transcripts do not include any type of disfluency. They contain only the content of the utterances. It is very important to remember that these transcripts may not be correct, and that mistakes may have been made in determining the content of the utterance. Do not accept the utterances as correct just because you are cueing into key words. Listen to the entire utterance and see if you agree with all the words that have been included, and then add the additional words that you hear along with all the disfluencies.

The purpose of this reliability testing is to determine the investigator's accuracy at identifying sound repetitions, syllable repetitions, single syllable word repetitions, multisyllable word repetitions, phrase repetitions, revisionincomplete phrases, interjections, disrhythmic phonations, and tense pauses. The following are definitions of these disfluencies:

1. Sound repetition: refers to the repetition of a single speech sound. Example: "s-s-see"

2. Syllable repetition: refers to the repetition of one or more syllables which are less than the entire word. Example: "ba-ba-baby" or "eleph-elephant"

3. Single syllable word repetition: refers to the repetition of a one syllable word. Example: "boy-boy"

4. Multisyllable word repetition: refers to a word that has more than one syllable and is repeated in its entirety. Example: "cowboy-cowboy" 
5. phrase repetition; refers to the repetition of two or more words. Example: "He was-he was-he was my friend"

6. Revision-incomplete phrase: refers to instances in which modifications to a phrase are made in order to change the content, grammar, or pronunciation. Example: "I want, do you want some?" or "I buy, I bought some"

7. Interjection: refers to extraneous sounds that do not add meaning to a speaker's text (Johnson, 1959).

8. Disrhythmic phonation: refers to audible or silent continuation of a sound or articulatory posture which interferes with the rhythmic flow of speech. This type of disfluency occurs within words and includes broken words. Example: "I was g---oing home"

9. Tense pause: refers to disfluency which is unintentionally produced between part words, words, and nonwords when at the between point in question there are barely audible manifestations of heavy breathing or muscular tightening.

Procedure for transcription and identification of disfluencies:

An individual not involved with this study has prepared five randomly selected content transcripts. Reliability raters are given these transcripts. The investigator then plays the corresponding segment of the videotape that matches the content transcripts. The investigator will initially show the reliability raters all ten utterances at once while the raters observe the utterances in their entirety. The investigator then plays the videotape segment again, showing the raters one utterance at a time. The raters are responsible for filling in all missing parts of the transcripts, including words that have been deleted, and all disfluencies. The raters then identify the target disfluencies. It should be noted that the raters are responsible for making any changes in the transcripts due to errors made by the individual selecting content transcripts. 
The raters are allowed to review the utterances as many times as requested. There is no talking or discussion during reliability testing, except for requests to review an utterance.

The following rules should be used when transcribing and identifying disfluencies:

1. Raters are responsible for identifying sound repetitions, syllable repetitions, single syllable word repetitions, multisyllable word repetitions, phrase repetitions, revision-incomplete phrases, interjections, disrhythmic phonations, and tense pauses.

2. Identify disfluencies with the following markings over the disfluencies:

$S d R \quad$ sound repetition

Sy $R$ syllable repetition

SSWR single syllable word repetition

MSWR multisyllable word repetition

$\mathrm{Ph} R \quad$ phrase repetition

RIP revision-incomplete phrase

I interjection

DP disrhythmic phonation

TP tense pause

3. No matter how may times a sound, syllable word or phrase is repeated in a single incidence, it is only credited as one disfluency.

4. An utterance may have a combination of any of the nine disfluencies, and should be credited as separate disfluencies if this occurs. Example: "Ky-Kyle-Kyle" would be scored as one syllable repetition and one single syllable word repetition.

5. Repetitions of the first part of a contraction, such as "I-I'm" and "it-it's" should be credited as sound or syllable repetitions.

6. Any interjection which separates a sound or syllable repetition, single syllable or multisyllable word repetition, phrase repetition, or revision-incomplete phrase, does 
not negate the repetition. Example: "They, um, um, They" or "We went, uh, I bought ice cream" or "What is this, um, What is this?"

7. Repetitions of interjections are not credited as either sound, syllable, or word repetitions. Example: "uh, uh" or "um, um" or "well uh, well uh"

Reliability training

A training session was conducted by the investigator using the same procedures as outlined above. The training session included practice identification of three different content transcripts. The reliability raters had to be $100 \%$ in agreement with each other. Differences were discussed until everyone agreed over disfluency identification. 